\title{
REDECRIAR MOEDA FLOR: TEMPOS DE TRABALHO SOCIAL NA ILHA DAS FLORES (PORTO ALEGRE, RS, BRASIL)
}

\author{
Andréa Jaeger Foresti ${ }^{1}$
}

Este relato consiste em um paper apresentado no Colóquio Tempo e Trabalho no dia 16 de maio 2014 no Instituto Federal Rio Grande do Sul em Porto Alegre, em evento promovido pelo projeto Banco de Imagens e Efeitos Visuais do Programa de Pós-Graduação em Antropologia Social (IFCH, UFRGS).

Porto Alegre é uma cidade banhada por um rio, mais do que isto, sua composição aquífera está relacionada a um delta, o Delta do Jacuí. Isto dispõe também sobre uma territorialidade insular que margeia a península. Desde o século passado, a comunicação rodoviária predomina para interligar as diversas espacialidades, em especial uma sequencia de pontes de concreto armado e uma estrada federal (BR 290) se estendem sobre os espaços insulares em direção ao centro e ao sul do estado gaúcho, Rio Grande do Sul.

Nestas ilhas, habita uma importante população com características diversas. A maioria da população descende de comunidades de pescadores, navegadores, plantadores hortigranjeiros e trabalhadores empregados na capital, compondo uma população de baixa renda. Em geral, as ilhas se caracterizam como região de banhados, com registros de frequentes inundações, aterros para combater essas inundações, construções irregulares e um grande contraste entre moradias precárias e as mansões de beira de rio. (Costa, 2012). De fato um importante espaço da orla encontra-se hoje enobrecida, com terrenos explorados pela política imobiliária e, um passeio de barco pela orla, revela aos olhos do turista, mansões com ancoradouros privados para barcos potentes. Mas concentremo-nos em apresentar a população com características ribeirinhas, vivendo em casas próximas às ribanceiras dos rios, algumas vilas próximas aos pilares das pontes e outras adentrando o complexo de ilhas que formam o Delta do Jacuí.

Uma destas Ilhas chama-se Ilha das Flores. A Ilha das Flores é uma das ilhas do Delta do Jacuí, situado na região metropolitana de Porto Alegre/RS. O Delta abrange seis municípios: Canoas, Charqueadas, Eldorado do Sul, Triunfo, Nova Santa Rita e Porto Alegre. Trata-se de uma unidade mista de conservação, constituída tanto de áreas

\footnotetext{
${ }^{1}$ Universidade Federal do Rio Grande do Sul, Brasil.
} 
configuradas como Parque quanto de áreas que se configuram como Área de Proteção Ambiental. A diferença é que as áreas de Parque, segundo a legislação, são de domínio público e não podem ser ocupadas. E nas Áreas de Proteção Ambiental, pode haver ocupação, porém, com restrições.

Um nome nem tão estranho para uma geração de porto alegrenses e mesmo brasileiros que consumiram o filme crítico do cineasta Jorge Furtado intitulado Ilha das Flores, de 1989. Buscando uma crítica ao consumismo da sociedade globalizada, o filme retrata uma população vivendo de restos e de lixo na ilha. Uma publicidade que é percebida pela população como um estigma de difícil superação.

A ocupação de áreas da Ilha das Flores foi iniciada na década de 1970 por população de baixa renda, em faixas de domínio da rodovia, em função do fácil acesso através da malha viária da BR 116 e BR 290, caracterizando moradias precárias em áreas alagáveis. (Costa, 2012).

Esta localidade é palco de muitas pesquisas e intervenções sociais. A minha relação com esta comunidade, da mesma forma, se caracteriza por uma pesquisa e uma ação social. É preciso relatar o percurso desta pesquisa-ação situando, antes de mais nada, a minha trajetória profissional para o reconhecimento dos campos de conhecimento científico e social de atuação como pesquisadora. O tema preeminente das atividades de pesquisa e social, no local, se constitui nas condições de habitação dos habitantes da Ilha das Flores, vulneráveis às situações de riscos ambientais como inundações.

Para contextualizar minha trajetória profissional, inicio pela minha formação em Engenharia Civil finalizada em 1986. Uma vocação para o social foi a motivação para desenvolver outro curso, desta vez Serviço Social finalizado em 2005. Neste ano eu participei junto com profissionais e colegas do Serviço Social da criação de uma Organização Não Governamental (ONG) chamada Redecriar e é pela minha atuação nesta ONG que participo de uma ação social na Ilha das Flores. Paralelamente a esta militância, desenvolvo de 2007 a 2009, em São Paulo, curso de especialização em Meio Ambiente e Sociedade na Fundação Escola de Sociologia e Política de São Paulo (FESP/SP) e, de 2013 a 2015, desenvolvo o mestrado no Programa de Pós-Graduação em Engenharia Civil (PPGEC) da Universidade Federal do Rio Grande do Sul (UFRGS). Desde 2013 iniciei um diálogo entre a questão dos riscos socionaturais com a profissional em Antropologia, sob a orientação da Profa. Cornelia Eckert, parceria que 
me inseriu no campo de conhecimento da antropologia que contribui para uma guinada desta pesquisa e ação que trago neste relato.

O problema das condições de moradia para populações de baixa renda se tornou um tema de estudo desde 2005, na qualidade de pesquisadora do projeto interdisciplinar sobre Construções Sustentáveis, do Núcleo de Estudos sobre a Inovação da Edificação (NORIE, UFRGS). Neste âmbito elaborou-se uma proposta de loteamento em uma área de proteção ambiental, seguindo os pressupostos da sustentabilidade. A minha atribuição no grupo era elaborar um programa para atender à dimensão social do desenvolvimento sustentável para a área em estudo. Para tal empreendimento foi crucial fundamentar o projeto com estudos sobre legislação ambiental e desenvolvimento sustentável.

Neste tema também a referida ONG (grupo de profissionais do Serviço Social), se inclina ao estudo do desenvolvimento sustentável, motivação para criar o Projeto Reciclando a Cidadania, que tinha como objetivo ressignificar a cidadania infantil no contexto escolar público a partir de uma metodologia fundamentada na Educação Ambiental. Este projeto foi aplicado em uma escola da zona leste de Porto Alegre e articulava alunos, professores, pais e agentes comunitários de saúde, no ambiente escolar e na associação comunitária.

O resultado desse processo foi a dinamização da ONG Redecriar, tendo como Missão, "Promover educação para sustentabilidade e geração de renda dirigida para crianças, jovens, adultos e organizações" e visão, "Ser uma fonte de referência pública em educação para a sustentabilidade." A intenção do grupo era levar a metodologia do trabalho em redes para a prática, articulando escolas de uma mesma região, com atividades do projeto e, assim, propagar o serviço à justiça social, a garantia do exercício à cidadania, ampliando a participação de grupos socialmente excluídos. Porém, os recursos captados para o desenvolvimento do projeto, a partir da parceria estabelecida com a Empresa Gerdau, em Porto Alegre, no ano de 2007, precisavam ser aplicados no entorno da sede localizada na Av. Farrapos e dessa forma, nós saímos da região leste e dirigimos nossa atuação para o centro de Porto Alegre, articulando somente as duas escolas para onde os recursos foram direcionados.

Em 2010, um projeto da ONG foi selecionado para o Programa Criança Esperança e, com os recursos coordenados pela UNESCO, nos conduzimos para as proximidades da região sul. Em 2011, com a aprovação de nosso projeto em um edital 
do Instituto Oi Futuro, nós chegamos à Escola Estadual de Ensino Fundamental Oscar Schmidt, localizada na Ilha das Flores.

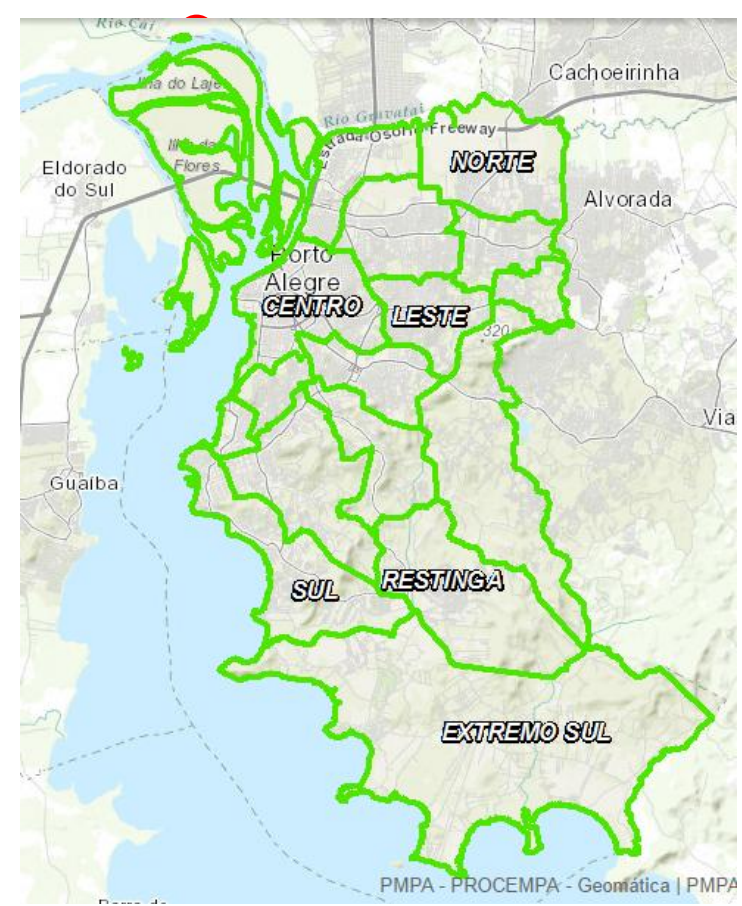

Figura1: Pontos de atuação da ONG Redecriar em Porto Alegre.

Uma das componentes da ONG Redecriar era a pesquisadora de mestrado do Núcleo de Pesquisas em Violência da PUCRS, Simone Barros de Oliveira. O projeto da Redecriar passou a ser conhecido pela consultora da UNESCO, também pesquisadora do mesmo núcleo de pesquisas. Na ocasião dessa consultora indicar um projeto a concorrer para uma premiação promovida pela Fundação Maurício Sirotsky Sobrinho, uma das indicações foi para o Projeto Reciclando a Cidadania, classificado em $3^{\circ}$ lugar, na categoria Meio Ambiente.

A empresa Gerdau considerou muitos pontos favoráveis no trabalho desenvolvido nas duas escolas e planejou a continuidade do mesmo para o ano de 2008. Porém, este foi o ano da crise econômica mundial. Nessa perspectiva os recursos para projetos sociais foram suspensos. Nesse período eu estava morando em São Paulo e atuava na ONG Redecriar com o planejamento e monitoramento de resultados dos projetos executados por minhas colegas em Porto Alegre através da elaboração de relatórios enviados via Internet. Nesse período fiz um curso de especialização na FESPSP e conheci uma gestora ambiental que produzia joias ecológicas: a Val Ribeiro. 
Patrocinada pela Empresa Gerdau, a Val Ribeiro ministrou um curso para as integrantes da ONG Redecriar em Porto Alegre, sobre formas de reaproveitamento de embalagens plásticas. Este curso foi matéria de jornal, que conectou uma profissional do Programa "Primeira Infância Melhor" (PIM) ao site da ONG Redecriar, interessada em estabelecer uma parceria com o grupo de famílias que era atendido na Ilha das Flores.

Em 2008 nós respondemos ao edital do Prêmio Valores do Brasil, promovido pelo Banco do Brasil S.A. em parceria com a Universidade Federal de Brasília (UnB). Além do troféu, nosso projeto foi contemplado com $\mathrm{R} \$ 50.000,00$. Parte desse valor foi aplicado na Ilha das Flores, com famílias do Programa Infância Melhor.

Os índices que apresentaram maior vulnerabilidade social no município de Porto Alegre nos quesitos renda, escolaridade e domicílios com esgotamento sanitário não adequado se encontram na região do Delta do Jacuí. (PMPA, 2007)

Quando chegamos à ilha, mais especificamente na Associação dos Ilhéus Ecológicos, em 2008, conhecemos o líder comunitário, Juramar Vargas, que já afirmava:

Sou sozinho nas reuniões do Plano de Manejo, nos fóruns coletivos da questão das águas, da articulação das redes... enfim, precisamos ser mais representativos nos espaços coletivos. (Juramar Vargas, 2008).

Esclareço que Plano de Manejo é um documento que tem como objetivo, regular o uso adequado das áreas, bem como o manejo dos recursos naturais. De responsabilidade da Secretaria Estadual do Meio Ambiente - SEMA, se encontra em fase de conclusão, cabendo à Fundação Zoobotânica a parte que se refere ao Parque Delta do Jacuí e à MRS Estudos Ambientais a parte do Plano de Manejo que faz referência à Área de Proteção Ambiental do Delta do Jacuí (APADJ).

Desde 2008 o Plano de Manejo do Delta do Jacuí está em processo de definição pela Secretaria Estadual do Meio Ambiente (SEMA). Em uma das reuniões do Plano, a Fundação Zoobotânica (FZB) apresentou os principais impactos que as características locais podem gerar sobre a vida dos moradores do Delta do Jacuí: exposição a riscos socioambientais, desapropriações, realocações de algumas famílias.

Em janeiro de 2009, de volta a residir em Porto Alegre, participei do processo de seleção do projeto "Redecriando Flores na Ilha" com a ONG Redecriar, que complementava aquele que fora introduzido em 2008 com o valor do Prêmio, capacitando seus integrantes para o beneficiamento de embalagens plásticas que se configuram como "lixo". Aprovado pelo Edital Rede Parceria Social II, promovido pela 
Secretaria da Justiça e Desenvolvimento Social do Estado do Rio Grande do Sul, este projeto teve como foco, a geração de trabalho e renda, pautado no reaproveitamento de resíduos sólidos. O eixo norteador do projeto consistiu na Educação para Sustentabilidade, visando maior consciência ambiental por parte da comunidade.

A reportagem do Jornal do Comércio, divulgada no período do desenvolvimento do projeto, evidencia parte da estratégia que tentava transformar o lixo, presente nas ilhas do Delta do Jacuí, em adorno.

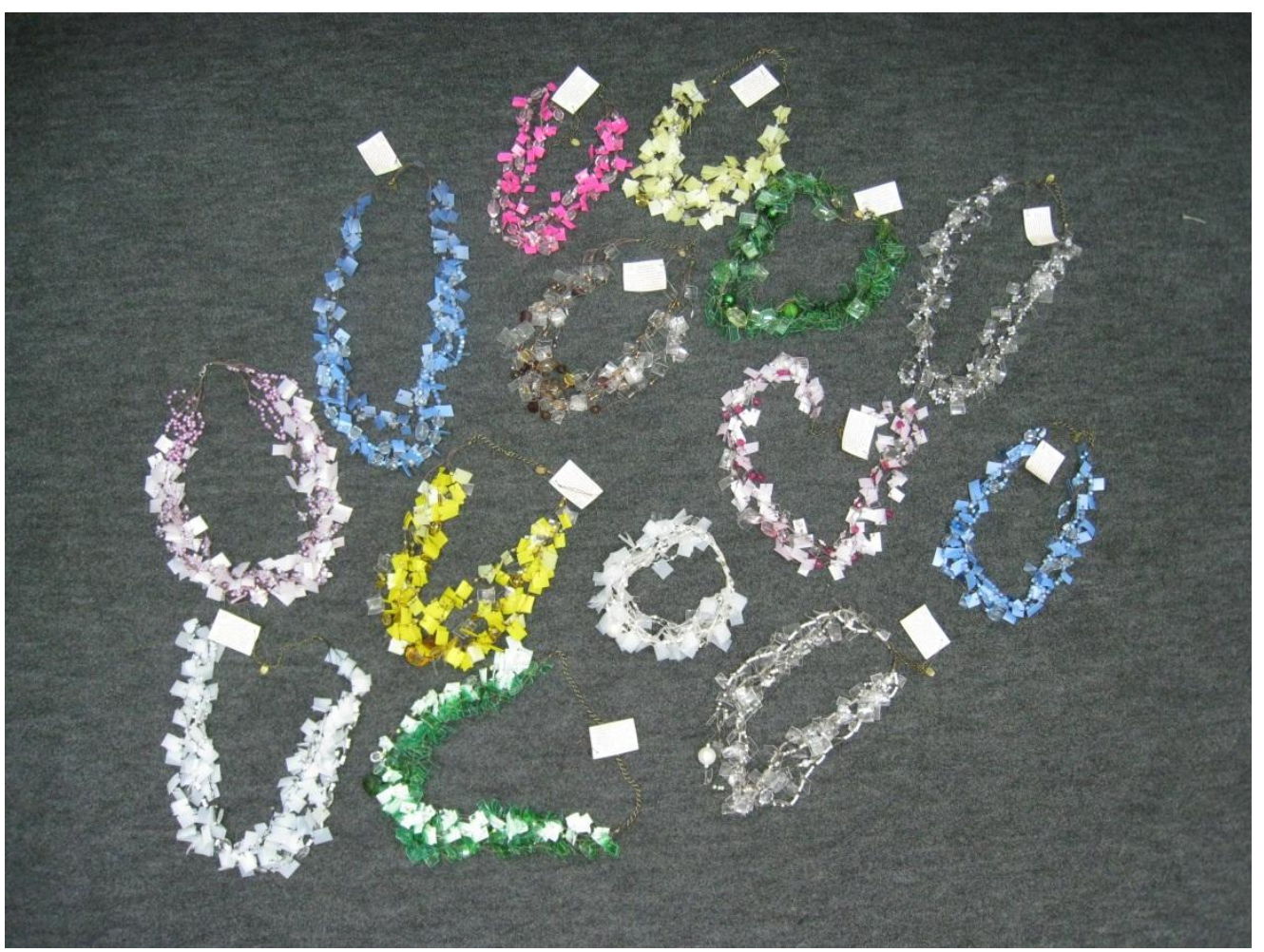

Figura 2: Joias Sustentáveis produzidas com o reaproveitamento de resíduos.

Em 2011 participamos do processo de seleção de Tecnologias Sociais ${ }^{2}$, promovido pela Fundação Banco do Brasil. O processo resultou na certificação das Joias Sustentáveis como Tecnologia Social. Além de atribuir valor ao trabalho coletivo da comunidade, fortalecendo cada integrante do grupo, contribuiu com a valorização do histórico da ONG Redecriar no processo de aprovação dos projetos inscritos em editais. Também neste ano foi selecionado no Edital promovido pelo Instituto Oi Futuro, o

\footnotetext{
2 Tecnologias Sociais, de acordo com a Fundação Banco do Brasil, compreende produtos e/ou metodologias que envolvem comunidades e gerem transformações sociais.
} 
Projeto de Educação para Sustentabilidade na Escola Estadual Oscar Schmidt. Este foi o período em que eu me inseria como aluna especial de mestrado, no núcleo de pesquisas sobre Gestão de Riscos de Desastres (GRID), inserido no Programa de Pós-Graduação em Engenharia Civil (PPGEC) da Universidade Federal do Rio Grande do Sul (UFRGS).

Em 2012 o Projeto Redecriando Moeda Flor na Ilha foi aprovado pelo governo do estado do RS e desenvolvido com aproximadamente vinte mulheres, com o objetivo de organizar o trabalho comunitário para geração de renda, fundamentado na TS Joias Sustentáveis. Trata-se de uma metodologia de incentivo à participação social, em que, a presença nos encontros dava acesso a 2 moedas-flor e, depois de quatro a seis encontros, as moedas eram trocadas por utensílios domésticos no sentido de reduzir a necessidade de donativos e programas sociais.

A participação social foi trabalhada em duas dimensões: a dimensão da assistência e a da política. A estratégia política se baseou no trabalho coletivo para produção das joias sustentáveis e a estratégia da assistência contemplava o acesso da comunidade aos utensílios domésticos, mediados pela frequência nos encontros, com a troca de moedas-flor. A dimensão política também era contemplada a partir da capacitação para técnicas cooperativas, contabilidade para a produção coletiva, meio ambiente e percepção de riscos para redução das vulnerabilidades socioambientais.

Pressupõe-se que com a qualificação da percepção de riscos a comunidade tornase mais capaz de reduzir suas vulnerabilidades socioambientais. Essa metodologia foi desenvolvida a partir da parceria entre a Redecriar e o GRID/PPGEC da UFRGS, composto por uma equipe multidisciplinar das áreas da Engenharia, Arquitetura, Serviço Social, Psicologia e Comunicação Social. O trabalho foi realizado no período entre agosto /2012 e janeiro/2013 e contou com a participação de alguns moradores do Projeto Redecriando Moeda Flor, porém, com a inserção de quatro crianças e de um adulto do sexo masculino.

Os principais resultados alcançados com o desenvolvimento deste trabalho foram:

* integração entre Núcleos de Pesquisa da UFRGS: Engenharia Civil, Geografia, Psicologia, Antropologia;

* qualificação da percepção de riscos por parte da comunidade expressa em propostas para enfrentamento dos riscos socioambientais aos quais está exposta;

* qualificação do processo de participação social expresso no envolvimento da comunidade com as questões do Plano de Manejo; 
* reconhecimento público da metodologia como Tecnologia Social. Logo após o término das atividades de percepção de riscos a Fundação Banco do Brasil abriu novo edital para seleção de Tecnologias Sociais e nós, do GRID/PPGEC, inscrevemos a metodologia, que em outubro/2013 foi certificada como TS.

Os impactos desse processo podem ser percebidos na medida em que comparamos os depoimentos do líder comunitário, desde o primeiro momento em que se estabeleceu a parceria entre Redecriar e Associação dos Ilhéus Ecológicos, em 2008. Tanto em 2008, quanto em 2012, quando chegava o grupo de pesquisadores do PPGEC, o líder repetia as mesmas palavras:

Sou sozinho nas reuniões do Plano de Manejo. Precisamos ser mais representativos nos espaços coletivos. Juramar Vargas Ilha das Flores, Ilha das Flores, agosto de 2012.

O terceiro momento se refere à última atividade da metodologia, realizada em janeiro de 2013, quando o líder afirmava:

Estar com as crianças aqui, hoje, é ter esperança no futuro das Ilhas. Contar com o envolvimento do pessoal na reunião do Plano de Manejo na Ilha, na semana passada, é uma conquista! Juramar Vargas. Porto Alegre, janeiro de 2013.

Em 2013 iniciei o meu diálogo com autores da Antropologia, orientada pela Prof. Cornelia Eckert. O olhar antropológico sobre a experiência da Redecriar foi objeto de uma monografia da disciplina ministrada pelos professores Ruben George Oliven e Arlei Damo, que realizei na Pós Graduação da Antropologia em 2013. Trata-se de um estudo reflexivo sobre a minha experiência como gestora de projetos sociais da Redecriar com um grupo de moradores de áreas precárias em situação de risco de inundação. $\mathrm{O}$ estudo teve como base, autores que abordam categorias analíticas como: a teoria da dádiva, de Marcel Mauss; a teoria da dominação, de Pierre Bourdieu; e as normas de reciprocidade, de Marcel Hénaff.

Este exercício reflexivo partiu de ações desenvolvidas em um micro espaço comunitário (Ilha das Flores) e contextualizadas para uma perspectiva macro societária. Os objetos de doação (prática comum que deriva de ações filantrópicas na Ilha das Flores) e os programas sociais de governo foram identificados como objetos de questionamentos à luz desses autores. Uma das reflexões resultou em um olhar menos ingênuo às ações desinteressadas que chegam à Ilha das Flores. Passei a me questionar a quem realmente interessa que os moradores permaneçam ligados às práticas assistencialistas? 
O olhar antropológico ao Projeto Moeda Flor permitiu também, compreender que a dinâmica de troca, chegando aos utensílios domésticos como bens materiais, são carregados de significação social. Douglas e Isherwood (2004) afirmam que,

Em vez de supor que os bens sejam em primeiro lugar necessários à subsistência e à exibição competitiva, suponhamos que sejam necessários para dar visibilidade e estabilidade às categorias da cultura. É prática etnográfica padrão supor que todas as posses materiais carreguem significação social e concentrar parte principal da análise cultural em seu uso como comunicadores.

O que a valorização desses bens estavam comunicando? Era visível nas falas de algumas moradoras, que o consumo das mercadorias realizado através das trocas por moedas-flor, dizia algo sobre si mesmas, suas famílias e suas casas:

\footnotetext{
“o meu filho, que me dá uma mesada de R\$100,00, chegou em casa e logo viu que tinha coisa nova em cima do armário, e eu disse que aquilo era resultado meu e não do dinheiro dele...e ele disse que logo viu que eu tava rica". (LN)

"o meu marido não gostava que eu saísse toda quarta-feira de tarde e nunca entendia porque que eu insistia tanto em vir pra cá.. mas depois do primeiro mercado-flor, quando eu trouxe tudo o que eu consegui trocar pra casa ele viu! É uma forma de eu ajudar mais na nossa casa, com a nossa vida". (MS)
}

Alguns impactos foram percebidos com a certificação da TS Joias Sustentáveis pela Fundação Banco do Brasil. Algumas oportunidades surgiram para os Ilhéus Ecológicos, como a comercialização das peças em diversas feiras de economia solidária e a consequente complementação de renda; a aprovação do Projeto Redecriando Moeda Flor na Ilha; uma viagem à Torres para duas integrantes, ministrando uma oficina que gerou complemento de renda; uma viagem à Brasília para uma das moradoras auxiliar a gestora da ONG Redecriar na coordenação de um Curso de TS Joias Sustentáveis dirigido a um grupo de vinte missionárias que levaram a técnica ao Haiti como forma de superação à crise que derivou do terremoto de 2010, expandindo a TS para o exterior.

Essas oportunidades, além de proporcionarem ganhos imediatos que se referem à complementação financeira, também foram capazes de contribuir com o fortalecimento da autoestima e sentimento de pertencimento social, valorizando não somente a ação de uma integrante ou duas, envolvidas diretamente na ação, mas atribuindo valor a todo coletivo da qual ela(s) faz(em) parte.

Voltando à questão das doações, a teoria da dádiva aponta que para as relações se manterem, há uma sequência de atos de "dar-receber-retribuir". Goudbout (2002; 6397) afirma que quando a pessoa está impossibilitada de "retribuir", ela se torna no que 
recebe, alguém que não é contemplado em suas opiniões. Supõe-se que a comunidade que recebe doações humanitárias e permanece na condição de tutelada, põe em risco a sua identidade, se distancia de sua cultura local e tem grande chance de passar a adotar a cultura do doador, perpetuando um ciclo contínuo de recebimento. Dentre as consequências desse ciclo, pode haver a perda da liberdade, a perda de identidade por parte de quem assume a condição de recebedor do dom/doação.

Goudbout (2002) evidencia a visão de liberdade moderna como resultado da ausência de dívida e a definição sociológica de mercado como "vínculo social que visa escapar às obrigações normais inerentes aos vínculos sociais" (Goudbout, 2002: 82). Se há a valoração de um material, representado pela moeda, a dívida social deixa de existir, passa a se configurar como valor de troca.

A bibliografia etnográfica permitiu rever a ação da ONG Redecriar no nível micro comunitário. Espaço esse, onde incidem problemas e potências: assim como estão presentes problemas como o da ocupação de toda a margem do Rio Jacuí, por mansões que contrastam com moradias precárias; há também a especulação imobiliária, que consegue aprovar a implantação de condomínios de luxo, como o de Eldorado do Sul; e ainda há a sobreposição de leis em nível federal, estadual e municipal, que geram conflitos de gestão do território. Chegam para a comunidade, doações, programas sociais de governo, o nosso projeto de geração de trabalho e renda, a metodologia de percepção de riscos do GRID/UFRGS, e o projeto da Moeda-Flor. Embora o território conte com todos esses recursos, fundamentalmente, faltam políticas públicas que articulem todas essas questões de forma que se potencializem as ações desenvolvidas.

Pensar numa reconfiguração da sociedade pressupõe o reconhecimento das necessidades de cada cidadão em pequenos núcleos comunitários, e que esse reconhecimento das necessidades se propaguem de forma local, iniciando com o estímulo à participação comunitária e se expandam geograficamente, em rede, até alcançar dimensões globais. 


\section{Referências}

ABÉLÈS, Marc. Les Nouveuax Philanthropes. In: Les Nouveaux riches - un ethnologue dans la Silicon Valley. 2002, p. 123-178.

BOURDIEU, Pierre. É possível um ato desinteressado? In: Razões Práticas. Campinas, Papirus, 1996, p. 137-61.

BRASIL - Emenda Constitucional nº 64, de 2010, no artigo $6^{\circ}$ da Constituição Federal BRASIL - Lei 12.471/2012

COSTA, Vania Mara Angelo da. Bióloga. Gestora da APA Estadual Delta do Jacuí. Parque e APA Estadual Delta do Jacuí. 2012

DOUGLAS, Mary e ISHERWOOD, Baron. O Mundo dos Bens. Para uma antropologia do consumo. Rio de Janeiro, Editora da UFRJ, 2004.

ECKERT, Cornelia; ROCHA, Ana Luiza Carvalho da. "Etnografia: saberes e práticas". In: PINTO, Céli Regina Jardim e GUAZZELLI, César Augusto Barcellos (Org.). Ciências Humanas: pesquisa e método. Porto Alegre: Editora da Universidade, 2008, p. 9 a 24. Série Graduação.

GOUDBOUT, Jacques. Homo donator versus homo economicus. In: Paulo Henrique Martins (org.). A dádiva entre os modernos. Discussão sobre os fundamentos e as regras sociais. Petrópolis, Vozes, 2002, p. 63-97.

HÉNAFF, Marcel. Sur la norme de reciprocitè. In: Mauss Vivant. Séminaire international, 1320 Juin 2009, Cerisy-la-Salle, p.67-77.

ONG Redecriar, Banco de Imagens. 2005 - 2013.

PMPA, 2007. Mapas e Indicadores das Vulnerabilidades Sociais. Prefeitura de Porto Alegre.

Recebido em: 16/03/2015

Aprovado em: 23/05/2015 